\title{
The Analysis of How Food Advertisements Attract Recipients Attention-Based on Ogilvy's Theory
}

\author{
Jingbo Feng
}

\author{
HNU-ASU Joint International Tourism College, Hainan University, Haikou, Hainan 570228, China \\ *Corresponding author. Email: angela@cas-harbour.org
}

\begin{abstract}
Food is essential for human's life. Food advertisements are targeting on people of distinctive ages with distinguished requirements. And it is common to see that some of the food advertisements are continuously coming into people's eyes through a novel advertising form, even if people totally know it is about the same food, but they still watch it repeatedly. Therefore, this paper aims at analyzing how food advertisements appeal people to buy their products in terms of Ogilvy's theory, focusing on food advertisements themselves. After analysis, people could have preliminary understanding of Ogilvy's theory and the relationship of food advertisements and Ogilvy's theory. Case analysis is used in this paper, and three to four pieces of advertisements are targeting on each of the method of Ogilvy. In the end, the phenomenon that people have their desire to buy food because of food advertisements, which demonstrates that Ogilvy's advertising methods could potentially arouse consumers' interests to buy certain food and truly believe that such food is worthwhile buying.
\end{abstract}

Keywords: food advertisement, the Ogilvy's theory, research analysis

\section{INTRODUCTION}

Food, as the material guarantee for human survival, plays an important role in satisfying human material needs[4]. Researchers have studied about linguistic analysis of English food advertising language or artistic expression method of graphic creativity in food advertisement design. They paid more attention to how to express an attractive advertisement to recipients in other aspects but seldom analyzed the Ogilvy's theory. In terms of the relationship between food advertisements and the Ogilvy's theory, lots of items in Ogilvy's theory could be targeted to some certain food advertisements and ulteriorly analyzed how the food advertisement demonstrates one of the Ogilvy's theories. When customers facing so many advertisements, there are a vast number of food advertisements which could be used as data to help find cases and finish research analysis. Food is divided into different types, thus when analyzing them, it is better to choose different products such as beverage and dry snacks. So the research analysis could be more objective and all-rounded. The Ogilvy's theory is a very important theory in advertising strategies. His advertising methods of impacting recipients may inspire other advertisements, not just food advertisements, to change the mode in order to attract more customers to buy the food products, so that this is the reason why this paper connects food advertisements with the Ogilvy's theory.

\section{OVERVIEW OF OGILVY'S THEORY}

Ogilvy used five methods to explain brand advertising theory, providing accurate information, establishing a brand image, providing an organizing 'big idea', maintaining relevance and researching what works. So how do different types of food advertisements connect with the five methods in turn let people buy products successfully? The method of analysis is that three to four remarkable advertisements are selected, and each advertisement is matched with the five methods according to their different characteristics and different aims. After analyzing data, food advertisements which can be associated with one of the methods are further analyzed. Oppositely, some other food advertisements are useless and have no value to analyze continuously.

\section{RESEARCH ANALYSIS}

\subsection{Provide Accurate Information}

The factual information focuses on the original function of advertising: informing customers of a product's availability, such as its appearance, function and stuff. It could create credibility that reduces the reader's resistance. Coconut milk advertisement which is a TV advertisement directly shows the process of pouring white coconut milk into the bowl. Certainly, coconut milk is white as the advertisement's slogan said 'authentic coconut milk of coconut tree brand-not only fair but also tender.' Although this advertisement utilizes the rhetoric of metaphor to compare coconut milk's characteristics to human's characteristics, it truly illustrates the real characteristic of coconut milk and provides the accurate information of this product. Therefore, according to recipients' original recognition of milk, the explanation of 
ad's information is enough to be trusted and people would reduce the resistance on this advertisement.

\subsection{The Brand Image}

The brand image is like a product's personality. Ogilvy said advertisements are used to serve brand images, which means advertisements take the responsibility to demonstrate the products' characteristic and attract people to buy. Take Coca Cola as an example, the unique outer packing and red logo can be popped up in recipients' mind when mentioning this drink. Although Coca Cola designs its bottle and revises its logo for several times[5], it still leaves deep impression for consumers' taste buds, depending on its almost the same flavor. The brand image is associated with its advertisements, for instance, although nowadays other types of Cola are created and no matter how they propagandize through advertisements, some people may still choose Coca Cola because of its brand image.

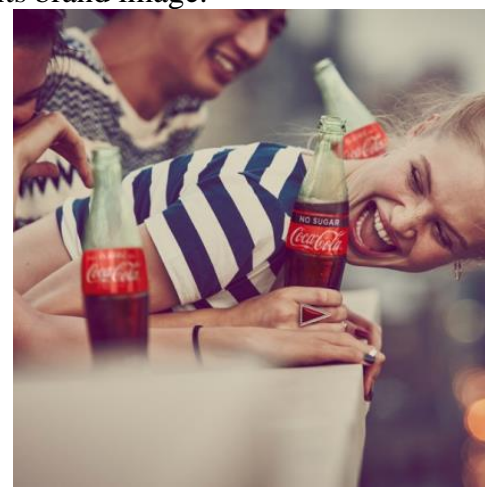

Figure 1 The brand image of Coca cola on the bottle[8]

In addition, the brand image of Ogilvy's methods means the image and the set of associations that the subject forms around the product. These associations may be largely arbitrary, even counterfactual. For example, a slogan of a sport drink's advertisement is that "Life is a sport, drink it up." Gatorade[6]. Firstly, life is not a sport. Secondly, this sentence has nothing to do with the thesis statement. Even the most important thing of the advertisement — "drink", does not appear at all. But when the readers take a closer look, the word "drink" implies that the ad is talking about a drink, while the word "sport" implies that the drink is a sport drink. The connection between "life" and "movement" actually draws lessons from the saying that "life lies in movement". The essence of sports drinks also makes the audience have a kind of reasoning that "sports drinks are good for sports, life lies in sports, so sports drinks are good for life", thus making people be willing to buy their drinks.

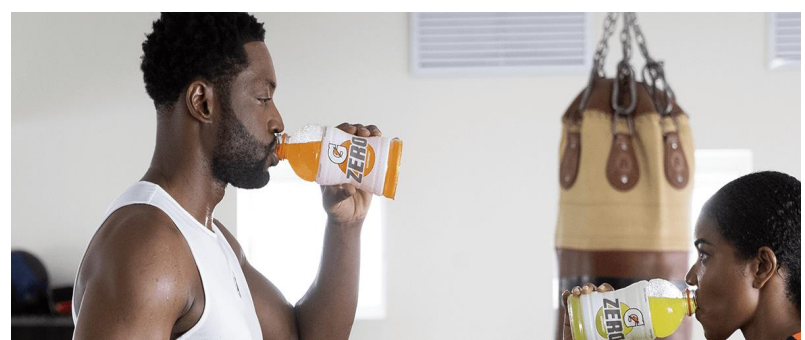

Figure 2 People drink Gatorade after doing sport[9]

\subsection{Provide an Organizing Big Idea}

The big idea is the central association that fixes the brand image. A particular event or image takes on a symbolic value. It stands for a whole way of life, with emotions and expectations. However, big idea is not conscious to come up with but unconscious and has to be well-informed. Before inventing a big idea, a substantial number of information has been potentially injected into advertisers' mind. In 2008, depending on Chinese traditional culture, the advertisements of Orion pie were integrated into the concept of 'love and kindheartedness', which is from The Analects of Confucius. The brand concept of good friends is to insist on doing things with heart and treating people with heart[2]. For example, the main character and his friends started to eat Orion Pie when he was having birthday party. However, one of his friends did not have this pie and felt embarrassed. Then, the main character shared his own Orion pie with his friend. Actually, 'sharing' are involved in the concept of 'love and kindheartedness'. This concept actually is formed for a long time in Chinese history and it is not mentioned and considered in our daily life all the time but it is important. Hence, when advertisers need to create advertisements for a certain food, this concept can be popped up in advertisers mind and utilized. As for Orion Pie's advertisement, the warm and peaceful atmosphere are showed in the short video impresses audience a lot. Also, this pie could be eaten by people in different ages. The advertisements are connected with audience's psychology and make audience feel moved and emotional, advertising creativity is a combination of innovative ideas, which makes the traditional culture of China present in the form of advertising creativity, and not only achieves the function of inheriting the traditional culture, but also attracts consumers [6].

\subsection{Stay Relevant}

This method means that the advertisement inserts itself within the subject's preexisting associative networks and knowledge. For example, Poli food company's 'Poli seaweed' is a kind of snack which is convenient to eat and nutritious for people and its advertising slogan "I know the taste of the sea" is deeply rooted in the hearts of recipients. 'I' could be understood from two perspectives. The instructions of the word "I" on behalf of the merchant, and advertising strongly presents the merchants' self-confidence, who knows how to make the pure seaweed flavor and satisfy the audience's taste. In addition, 
"I" is regarded as a consumer, indicating consumers should try Poli seaweed if they want to know the sea's taste. It is evident that seaweeds grows in the sea, so it is the basis of advertisements that can insert subjects into the preexisting associative knowledge. In addition, the creative advertising slogan is added up with innocent and loud voice of children, illustrating a lively and upward product image for consumers and motivate them to buy.

\subsection{Research What Works}

Although people respond strategically to advertisers' who attempt to control their mind by advertisements. Rational appeals are based on consumers' cognition, while emotional appeals are aiming at arousing consumers' resonance and touching their hearts so as to change their concepts and behaviors[3]. Human perceptual psychology will help determine what types of ads are easily gotten. Therefore, advertisers may find a tacit method to make consumers naturally accept the advertisements and buy the products. Some advertisers create food ads in telling stories or showing certain plots, such as a short TV serial or film, to let recipients have interests to watch the food ads. For example, on February 5, 2012, the online premiere of the micro film advertisement (Ili Milk Tablets) "the girl who doesn't talk" was warmly welcomed by netizens, mainly college students, as soon as it was released. The success of this micro film advertisement was attributed to the exquisite storyline, which started from setting suspense. As the plot developed, the information was conveyed by the advertisement and gradually presented to the audience. The advertisement focused on the life experience of "love", which almost every young person has. It also presented the process of love between young men and women in a romantic and fresh style with simple and concise narrative structure. Any advertisement with a story is fascinating since the story has the twists and turns of the plot, which is eye-catching and worthwhile continuously watching. Meanwhile, not only do this kind of advertisements show dramatic stories, they also give recipients necessary information of products and potentially prompt them to buy.

\section{DISCUSSION}

The Ogilvy's theory is well-organized and detailed, which also inspires advertisers to have creative mind in order to make advertisements gain the above average quality. When facing so many food advertisements, it is easy to target every advertisement to each method of this theory. Advertising is a kind of art, the Ogilvy's theory shows that different food advertisements could use these methods to have valid effects in turn attracting more recipients to know and buy the food products. Ogilvy mentioned that food advertisements could be relatively successful if combining with humor, slice of life, testimonials, demonstrates and persuasive reasons[7]. However, the advertising methods in the Ogilvy's theory may not be the most comprehensive to analyze all the advertisements, but through his theory, advertisements are classified. For example, some food advertisements show what the food looks like and the advertisements are truly same as the real food, so these advertisements could be involved in providing accurate information in the Ogilvy's theory. As for those advertisements which are connected with an actual world overlook or value, these advertisements could be involved in providing a big idea in the Ogilvy's theory. When food advertisements demonstrate food in motion and make food tempting, consumers may have more desire and appetite to buy corresponding food. Then, it is clear for us to know how advertisers potentially put the Ogilvy's theory into a food advertisement.

\section{CONCLUSION}

Ogilvy's methods are not explicitly following consumers' minds, but tacitly they are following consumers' minds. These theories could clearly explain why consumers buy this food instead of another one when facing so many kinds of food and food advertisements. Providing accurate information in order to gain consumers' trust and reduce the resistance. Some advertisements develop a brand image to exploit what people really need in order to make quick judgements and provide a "big idea" to give people a value of these advertisements. Based on different methods of the Ogilvy's theory, different food advertisements have been analyzed, which means food advertisers always use these methods to let customers to believe them and buy their products. As for this article, some of the methods and only several food advertisements are analyzed, thus it is not complete enough. However, in the future, other food advertisements should also be analyzed according to these methods of the Ogilvy's theory. In addition, food advertisements could be classified more specifically and each method of the Ogilvy's theory is analyzed in the case analysis, which could make people understand more clearly about Ogilvy's theory and the strategy of food advertisements.

\section{ACKNOWLEDGMENT}

First and foremost, I would like to show my deepest gratitude to my teachers and professors in my university, who have provided me with valuable guidance in every stage of the writing of this thesis. Further, I would like to thank all my friends and roommates for their encouragement and support. Without all their enlightening instruction and impressive kindness, I could not have completed my thesis.

\section{REFERENCES}

[1] Du, H. Q. (2010) The emotional assault of Hao Liyou. International public relations, (06):56-57. Retrieved from http://www.prmagazine.com.cn/. [Accessed on November/11th/2019] 
2(21):175. Retrieved from http://cmlt.goooc.net. [Accessed on November/23rd/2019]

of print public service advertising (Doctoral dissertation). Kunming, Yunnan: Kunming university of science and technology. [Accessed on November/16th/2019]

[3] Ja, N. (2019) Linguistic analysis of English food advertising language: a review of food English. China brewing,38(08):230.Retrieved from http://manu61.magtech.com.cn/zgnz/CN/volumn/home.sh tml. [Accessed on November/13th/2019]

[4] Jiang, Y. Q. (2019) Evolution of Coca-Cola brand culture(Doctoral dissertation). Ha Erbin, Hei Longjiang: Hei Longjiang university. [Accessed on December/8th/2019]

[5] Wang, Z. M. (2019) Development and innovation of traditional culture in advertising creativity. Media forum,
[6] Li, P. Y. (2017) Research on pragmatic presupposition of beverage English advertising slogans(Doctoral dissertation). Beijing: Beijing university of posts and telecommunications.

[7] Ogilvy, D. (1985) Ogilvy on Advertising. A Division of Random House, New York.

[8] From the official website (2019), retrieved from https://us.coca-cola.com/ [Accessed on November/23rd/2019]

[9] From the official website (2019), retrieved from https://www.gatorade.com/[Accessed on November/23rd/2019] 